\title{
Early intervention for bipolar disorder: current imperatives, future directions
}

\section{Intervenção precoce no transtorno bipolar: necessidades atuais, rumos futuros}

\author{
Matthew Taylor ${ }^{1}$, Rodrigo Affonseca Bressan², Pedro Pan Neto², Elisa Brietzke ${ }^{2,3}$ \\ ${ }^{1}$ Department of Psychosis Studies, Institute of Psychiatry, King's College London \\ 2 Program of Recognition and Intervention in Individuals at Risk Mental States, Department of Psychiatry, Universidade Federal de São Paulo, \\ São Paulo, Brazil \\ ${ }^{3}$ Interdisciplinary Laboratory of Clinical Neurosciences, Department of Psychiatry, Universidade Federal de São Paulo, São Paulo, Brazil
}

\begin{abstract}
Objectives: The objective of this article is to discuss the rationale/ background for early intervention in bipolar disorder. Method: Narrative review. Results: There are often significant delays before the diagnosis of bipolar disorder is made and effective management initiated. Growing evidence from both preclinical and clinical literature points to a clear need for improved early identification and early intervention in bipolar disorder. Increasing efforts are being applied to the identification of those at high risk of onset of bipolar disorder. It is hoped that identification of an early prodrome of illness will allow preventative measures to be taken. Conclusions: There is a clear rationale for improved early identification and early intervention in bipolar disorder.
\end{abstract}

Descriptors: Bipolar disorder; Early intervention; Review; Determination; Treatment outcome

\section{Resumo}

Objetivos: O objetivo do artigo é discutir os fundamentos para a intervenção precoce no transtorno bipolar. Método: Revisão narrativa. Resultados: Frequentemente existe um atraso significativo com relação ao momento em que o transtorno bipolar é detectado e o início do tratamento. Evidências crescentes oriundas de estudos pré-clinicos e clínicos apontam para a clara necessidade de melhorar a deteç̧ão e o tratamento precoces no transtorno bipolar. Esforços também tem sido direcionados para a identificaçâo de individuos em alto risco. Espera-se que a identificação do pródromo do transtorno bipolar permita a instauração de medidas preventivas. Conclusóes: Existem bases claras para o investimento na melhora da detecção e tratamento precoces do transtorno bipolar.

Descritores: Transtorno bipolar; Intervenção precoce; Revisão; Determinação; Resultado de tratamento

\section{Introduction}

Bipolar disorder (BD) is a major global health problem that leads to significant lifetime morbidity and mortality. While the onset of illness is typically in youth, there are often significant delays before the diagnosis is made and effective management initiated. Growing evidence from both preclinical and clinical literature points to the clear imperative for improved early identification and early intervention in $\mathrm{BD}$. In addition to this evidence in established $\mathrm{BD}$, increasing efforts are being applied to the identification of those at high risk of onset of $\mathrm{BD}$. Drawing from the success of such an approach in nonaffective psychosis, it is hoped that identification of an early prodrome of illness will allow preventative measures to be taken. Here we draw together the current evidence in these areas.
$\mathrm{BD}$ remains a clinical diagnosis. The two major diagnostic classification systems worldwide are the International Classification of Diseases, 10th edition (ICD-10) and the Diagnostic and Statistical Manual of the American Psychiatric Association, 4th edition (DSM-IV). In both systems, BD is characterized by episodes of mood disorder. The key feature differentiating $\mathrm{BD}$ from recurrent depressive disorders (major or unipolar depression) is the lifetime presence of mania or hypomania or mixed episodes. DSM-IV further distinguishes between bipolar I disorder, where mania is observed, and bipolar II disorder, where hypomania is observed alongside one or more episodes of major depression. The classification is expected to undergo at least some changes with the forthcoming fifth edition of DSM.

\author{
Correspondence \\ Dr Matthew Taylor \\ Institute of Psychiatry \\ PO63, London SE5 8AF UK \\ Tel: +442078481000 \\ Fax: +44 2078480976 \\ E-mail: matthew.j.taylor@kcl.ac.uk
}




\section{Global impact}

$\mathrm{BD}$ has a worldwide distribution. Clinical samples are likely to underestimate prevalence; the most accurate available estimates come from painstaking epidemiological household surveys. The recent National Comorbidity Survey - Replication (NCS-R) ${ }^{1}$ obtained data from 9282 Englishspeaking adults across the continental USA, finding lifetime prevalence estimates of $1 \%$ for bipolar I and $1.1 \%$ for bipolar II, with a further $2.4 \%$ having subthreshold BD. Similar estimates were obtained by the World Mental Health Survey Initiative $^{2}$, in which face-to-face interviews of 61392 adults across 11 countries in the Americas, Europe, and Asia were performed. Lifetime prevalences were $0.6 \%$ for bipolar I, $0.4 \%$ for bipolar II, $1.4 \%$ for subthreshold $\mathrm{BD}$, and $2.4 \%$ for the bipolar spectrum. A large proportion of those surveyed had severe symptoms and role impairment confirming the serious impact of the disorder.

$\mathrm{BD}$ is associated with increased mortality. A number of large studies of people admitted to hospitals with BD have found elevated mortality. In a study of over 15000 patients in Sweden, standardized mortality ratios (SMR) in BD for death by suicide were 15.0 for males and 22.4 for females, and for natural causes of death SMRs were also significantly elevated, with most excess deaths from natural causes ${ }^{3}$. Similar findings were observed in Denmark ${ }^{4}$. Interestingly, in a community sample, identifying all patients with a first presentation of bipolar I, not restricted to those admitted to hospital, an elevated risk of suicide was also described (SMR 9.77, 95\% confidence interval [CI] 4.22-19.24), but no significant increase in deaths by other causes was observed ${ }^{5}$. An elevated risk of suicidality is not restricted to those with bipolar I disorder. In a meta-analysis of 15 studies, rates of attempted suicide did not differ between bipolar I and bipolar II disorder ${ }^{6}$.

\section{Early Onset}

The onset of illness in BD is often in young adulthood. In an international study of 1566 patients across six sites using modern diagnostic criteria, the median age of onset for bipolar I was 24.3 years, and for bipolar II $30.1^{7}$. There is some evidence that age of onset characterizes different subgroups of $\mathrm{BD}$ patients. In a recent UK study of more than 1000 participants with bipolar I disorder, three distributions were observed; one group with mean onset age of 18.9, another with mean onset age of 28.3 , and a third group with mean onset age of 43.3 years ${ }^{8}$. The group with the earliest onset was found to have a stronger family history of mood disorders, and also some markers of greater clinical severity such as greater suicidality, more rapid-cycling, more episodes of mania and depression, and greater scores on lifetime measures of depressive symptoms.

$\mathrm{BD}$ can be rapidly recurrent even after a first episode. In a US study of 166 people followed up for two years after their first episode of mania, $40 \%$ went on to experience a new episode of mania or depression, and 19\% switched phases of illness without recovery'. Similarly, in a Canadian study of 53 participants with first episode mania, more than half experienced a new mood episode within the first year of follow-up ${ }^{10}$, and earlier age of onset significantly predicted increased recurrence.

Polarity of initial episode appears to play a role in predicting future illness course. In a follow-up of 303 first episode patients from Europe and the US over two years ${ }^{11}$, first episode polarity strongly predicted the preponderance of future illness. Similarly, a UK study of 553 participants with well characterized bipolar I disorder found that an initial depressive episode at onset was associated with a predominantly depressive polarity and more frequent and more severe depressive episodes ${ }^{12}$.

\section{Delayed diagnosis}

Diagnosis of BD appears to be commonly delayed in routine practice. An average delay of 10 years between first symptoms and first treatment was reported in a well-characterized international outpatient sample ${ }^{13}$. Similar delays were described by support group participants in the US diagnosed with $\mathrm{BD}$, of whom one third reported having waited 10 years or more before accurate diagnosis ${ }^{14}$. In a retrospective study of over 200 people in Australia, while their symptoms on average had initially started by the age of 18 , and medical treatment been sought at 24 years old, the median age at diagnosis was 30 years $^{15}$. The most common previous diagnosis in both these samples was of unipolar depression.

A delayed diagnosis may have a range of adverse effects. In studies of outpatients with BD, increased delay in diagnosis and initiation of appropriate treatment has been associated with increased severity of depression ${ }^{16,17}$, decreased quality of life ${ }^{16}$ and greater likelihood of attempted suicide ${ }^{18}$. Unsurprisingly, given these clinical adverse effects, healthcare costs have also been found to increase with each month of delayed diagnosis of $\mathrm{BD}^{19}$.

\section{Diagnostic error}

In the early stages of $\mathrm{BD}$, two key causes of diagnostic error can be differentiation from major depressive disorder or other psychotic illness. The differentiation of BD from unipolar depression represents a common clinical challenge. As it becomes clearer that the optimal management of bipolar and unipolar depression differs, with conventional antidepressants showing disappointing efficacy in recent studies and carrying risks of increased mood instability, the importance of making this distinction becomes greater. Inevitably, some people who experience only depressive episodes early in the course of their illness will 'convert' to bipolar on experiencing their first episode of hypomania or mania. A number of attempts have been made to differentiate episodes of bipolar and unipolar depression on the basis of observed symptoms. 
A recent synthesis noted that 'atypical' features such as hypersomnia, hyperphagia, and leaden paralysis, psychomotor retardation, psychotic features, pathological guilt, and lability of mood were more common in bipolar depression ${ }^{20}$. Bipolar depression was also associated with an earlier age of onset of first depressive episode, more prior episodes of depression, shorter depressive episodes, and a family history of BD. A prospective validation of this 'probabilistic' approach has yielded promising results ${ }^{21}$. Another recent comparison of symptom features between large numbers of people with unipolar and bipolar illness similarly linked the presence of psychosis, diurnal mood variation and hypersomnia during depressive episodes, and a greater number of shorter depressive episodes, with bipolar diagnosis ${ }^{22}$. There are thus emerging pointers towards the possibility of identifying those with a higher risk of a bipolar illness even before mood elevation is experienced.

Some people who have already experienced hypomania or mania are mistakenly diagnosed with recurrent depressive disorder. This may be made more likely since hypomanic symptoms may not necessarily be identified as pathological by the patient, and may thus not be spontaneously reported. Screening tools such as the Hypomania Checklist (HCL-32) ${ }^{23}$ and Bipolar Spectrum Diagnostic Scale (BSDS) ${ }^{24}$ may be of benefit, although symptoms identified may not reach current diagnostic thresholds for $\mathrm{BD}^{25}$.

Increasing interest is attached to the presence of 'subthreshold' bipolarity in people currently diagnosed with major depression, such as might be identified by these screening instruments. This has the potential to greatly expand the boundaries of BD. In a 20-year prospective community cohort study of young adults, it was found that a broad definition of bipolar II disorder gives a cumulative prevalence rate of $10.9 \%$, compared to $11.4 \%$ for broadly defined major depression ${ }^{26}$. Using current classifications, the prevalence of $\mathrm{BD}$ is lower than that of unipolar depression; for example, in the NCS-R study the lifetime prevalence of major depressive disorder was $16.6 \%$, whereas for bipolar I and II it was 3.9\% ${ }^{27}$. However, nearly $40 \%$ of study participants with a history of major depressive disorder had a history of subthreshold hypomania ${ }^{28}$. This more bipolar' subgroup had a younger age at onset, more episodes of depression, and higher rates of comorbidity than those without a history of hypomania, which suggests that the difference may come to be of clinical significance.

A proportion of people presenting with a first episode of apparently non-affective psychosis will go on to be ultimately diagnosed with BD. Psychotic features are not uncommon during mania. In the McLean-Harvard First-Episode Mania Study, studying people during a first manic/mixed episode of bipolar I disorder, most subjects $(88.6 \%)$ had some initial psychotic features?. In the McLean-Harvard International First Episode Project, patients hospitalized in a first psychotic episode were assessed by standard criteria at baseline and at
24 months $^{29}$. Of 500 participants completing the study, the authors found that initial diagnoses of bipolar I disorder remained stable in $96.5 \%$ of cases. However, over one quarter of changes in diagnosis were from another psychotic illness at baseline to bipolar I disorder after two years. It is therefore important to be alert for the development of $\mathrm{BD}$ in people with early psychosis.

\section{Comorbidity}

Comorbidity is common in BD. In the World Mental Health Survey Initiative, three quarters of patients had at least one comorbidity, commonly anxiety disorders and substance/ alcohol abuse ${ }^{2}$. Follow-up of a cohort of 591 individuals $(292$ men and 299 women) in Zurich, Switzerland, who received six waves of diagnostic interviews over a 20 -year period ${ }^{30}$, allowed for clarification of the chronology of that comorbidity. Participants with manic symptoms were found to be at elevated risk for the later onset of problems with alcohol, cannabis and benzodiazepines. Bipolar II disorder predicted problems with alcohol and benzodiazepines. By contrast, there is some evidence that anxiety disorders tend to precede the onset of $\mathrm{BD}^{31}$.

Personality disorder can also pose an important comorbidity ${ }^{32}$. The emotional instability of borderline personality disorder can lead to its being viewed as a differential diagnosis of $\mathrm{BD}$, or delay recognition of bipolar comorbidity. In clinical practice many patients with borderline personality disorder also meet diagnostic criteria for $\mathrm{BD}^{33}$.

\section{IIIness progression}

There is increasing evidence pointing to disease progression over time. Almost one century ago, Kraepelin noted that people with $\mathrm{BD}$ presented a progressively worse clinical course over time, with a shortening of inter-episodic period $s^{34}$. Strong evidence now confirms that recurrence rates increase with further episodes of illness ${ }^{35-37}$. This effect persists even when adjustments are made for individual differences in frailty toward recurrence.

There is evidence from cross-sectional studies that a worse prior course of illness is associated with greater neuropsychological dysfunction ${ }^{38}$. Even early in illness, impaired cognitive functioning has a major impact in functional outcome ${ }^{39}$. Consistent with this, with a greater number of episodes of illness requiring hospital admission comes a greater degree of sustained functional impairment, even in euthymic patients ${ }^{40}$.

There is evidence that progression may increase the risk of treatment resistance. In an analysis of multiple trials of olanzapine in the treatment of $\mathrm{BD}$, it was found that those in the earlier stages of illness had a more favorable response to treatment ${ }^{41}$. A similar effect has also been reported for response to lithium, although this is not consistent across all studies $^{42}$. A potential increase in treatment non-response is not 
restricted to pharmacological management. In a meta-analysis of psychological interventions to prevent relapse in $\mathrm{BD}$, it appeared that the psychological therapies were less effective in those with a high number of previous episodes ${ }^{43}$.

A substantial body of neuroimaging evidence now demonstrates abnormalities in brain structure in BD. For example, a major meta-analysis demonstrated enlargement of the lateral ventricles and increased rates of deep white matter hyper intensities in $\mathrm{BD}^{44}$. More recently, an analysis of individual patient data combined across eleven research groups demonstrated a reduction in overall cerebral volume with increased illness duration ${ }^{45}$. This reduction in cerebral volume with longer duration of illness is consistent with a neurodegenerative process in the pathophysiology of $\mathrm{BD}$.

How can this disease progression be understood? Post and collaborators proposed the 'kindling model', in which parallels were drawn between observations in the experimental induction of seizures, illness progression, and drug tolerance in affective disorders such as $\mathrm{BD}^{46,47}$. These clinical observations could be understood as reflecting long-term changes in gene expression and downstream consequences altering a balance between pathological and compensatory systems. More recently, Kapczinski and collaborators developed the idea of 'allostatic load', where the genetic background interacts with an accumulating burden of biological 'wear and tear' due to different environmental stressors and the effects of illness episodes themselves ${ }^{48}$. It appears that disease progression may reflect an interaction of multiple processes ${ }^{49}$. These may not be restricted to changes in neurotransmitter systems, but may include changes in inflammatory cytokines and neurotrophins, such as BDNF50, and mitochondrial dysfunction ${ }^{51}$ with increased oxidative stress ${ }^{52}$. Importantly, the convergence of preclinical and clinical data point to a key role for early and sustained preventative measures, not only to avoid episodes of illness itself, but also potentially to prevent the associated accumulation of neurobiological vulnerability factors.

\section{Management}

Comprehensive guidance on the management of $\mathrm{BD}$ is beyond the scope of this article and can be found elsewhere ${ }^{53}$. The major clinical problems can be considered the treatment of acute episodes of bipolar depression, manic or mixed episodes, and the prevention of relapse. Appropriate pharmacological management is a mainstay of effective treatment, although it is important to recognize that pharmacological agents need to be delivered as part of a coherent package of care that may also involve specific psychological therapies ${ }^{54}$ and other psychological and social support. For example, there is evidence that effective treatment of substance misuse comorbidity can improve both adherence and outcomes. In the STEP-BD study, patients with BD who experience sustained remission from substance use disorders fared better than patients with ongoing substance use disorders, but not as well as subjects with no history of substance-related problems ${ }^{55}$.
Recent years have yielded a much improved evidence base to guide general management. On the one hand, the increasing availability of systematic reviews and meta-analyses allows the existing literature to be better understood. Furthermore, independent, high quality, randomized controlled trials have begun to provide answers to some of the important clinical questions in the management of acute episodes of illness ${ }^{56,57}$ and prevention of relapse ${ }^{58}$. Key recent findings include increasing evidence that bipolar depression may require rather different management than unipolar depression ${ }^{59}$. Future studies could investigate whether the presence of predictors of bipolarity in unipolar depression warrants differential management, even if full diagnostic criteria for $\mathrm{BD}$ are not met. Remission from depressive symptoms is an important treatment aim, since even subsyndromal depressive symptoms are associated with functional impairment and disability ${ }^{60}$.

Preventative treatment is recognized as increasingly important. Traditionally, particularly in European guidelines, prophylactic medication has often been reserved for cases where multiple episodes of illness occur in rapid succession ${ }^{61}$, however, a case can be made for considering preventative medication after a single severe manic episode ${ }^{53}$.

As noted above, there is a growing theoretical rationale for early prevention. Some initial data suggest that lithium may play a neuroprotective role, preventing structural changes in hippocampus and amygdala ${ }^{45}$. There is also concrete clinical evidence of substantial benefits on major outcomes. Data from controlled trials indicate that people with $\mathrm{BD}$ randomized to receive lithium treatment have both decreased suicide rates and all-cause mortality ${ }^{62}$. Psychological interventions have an important role as an adjunct to pharmacological management ${ }^{63}$, with effects that appear to be sustained well after the course of therapy.

\section{Specialized early intervention services}

There remains uncertainty around whether there are specific differences in appropriate treatment models for the earliest stages of BD. The lesson of early intervention services for psychosis has been that they can offer substantial benefits including significant positive effects on psychotic and negative symptoms, secondary substance abuse, treatment adherence, and a higher satisfaction with treatment ${ }^{64}$. It appears that early treatment of psychosis allows for the use of lower doses of antipsychotic medication ${ }^{65}$. Multicenter randomized trials are underway to investigate whether similar specialized care in the early stages of severe affective disorders proves superior to treatment as usual ${ }^{66}$.

\section{Identifying at-risk individuals}

Building on the clinical and neurobiological evidence of disease progression outlined above, staging models are beginning to be developed ${ }^{67}$. Similarly to the approach taken for some general medical conditions, an effective staging model could provide a structure for assessment and most 
appropriately direct therapeutic efforts. These might include people in a prodrome to the onset of $\mathrm{BD}$ proper to whom preventative measures could be offered.

Can a prodromal period be clinically defined? A number of studies, both retrospective and prospective, have aimed to identify features of this period ${ }^{68}$. Taken together, these studies indicate that symptoms can predate the onset of BD proper by months to years and can be attenuated forms of bipolar symptoms, general symptoms common to a range of mental disorders, and personality traits, such as cyclothymia. However, none of these features show high sensitivity for progression to $\mathrm{BD}$. Another recent review concluded that the specificity of prodromal symptoms and signs appears to be ${ }^{l o w}{ }^{69}$. It has been noted that a bipolar prodrome may in some cases be indistinguishable from the schizophrenia prodrome based on clinical and neurocognitive measures currently used in high-risk schizophrenia programs ${ }^{70}$. Thus, clinical features alone may not prove sufficient for all cases.

Genetics play a major role in $\mathrm{BD}^{71}$. Estimates of heritability from twin studies place it at over $80 \%{ }^{72,73}$, and there is also a gradation of risk of mood disorder according to the degree of genetic relatedness ${ }^{74}$. Family history is thus a strong putative method for identifying people at elevated risk of developing BD. Observational studies found that the offspring of bipolar parents shows a high risk for psychiatric disorders, and specifically for early-onset bipolar spectrum disorders ${ }^{75-77}$.

A number of ongoing studies aiming to prevent conversion to $\mathrm{BD}$ combine family history with the presence of (nonspecific) symptoms to identify a high risk group for intervention. A recent Melbourne study identified at-risk groups by the presence of subthreshold mania, depression with cyclothymia, or depression together with having a first degree relative with $\mathrm{BD}^{78}$. These criteria showed some initial success in identifying people who would progress to a $\mathrm{BD}$ diagnosis. Specific intervention may prove valid for such groups. High rates of response have been reported in uncontrolled studies of young people with symptoms and a positive family history of $\mathrm{BD}$ for both valproate ${ }^{79}$ and quetiapine ${ }^{80}$. A version of family-focused treatment adapted for youth at high risk for BD (FFT-HR) has also been developed, with promising initial results in a similar group with active mood symptoms and a positive parental history ${ }^{81}$.

\section{Conclusions}

Growing evidence points to the clear clinical imperative for improved early identification and early intervention in BD. In particular, preclinical and clinical evidence points to the importance of early and sustained treatment for relapse prevention. In addition to this evidence in established $\mathrm{BD}$, increasing efforts are being applied to the identification of those at high risk of onset of BD. Drawing from the success of such an approach in non-affective psychosis, it is hoped that the identification of an early prodrome of illness will allow preventative measures to be taken.

\section{Disclosures}

\begin{tabular}{|c|c|c|c|c|c|c|c|}
\hline $\begin{array}{l}\text { Writing group } \\
\text { member }\end{array}$ & $\begin{array}{c}\text { Employ } \\
\text { ment }\end{array}$ & $\begin{array}{l}\text { Research } \\
\text { grant }^{1}\end{array}$ & $\begin{array}{c}\text { Other } \\
\text { research } \\
\text { grant or } \\
\text { medical } \\
\text { continuous } \\
\text { education }\end{array}$ & $\begin{array}{l}\text { Speaker's } \\
\text { honoraria }\end{array}$ & $\begin{array}{c}\text { Ownership } \\
\text { interest }\end{array}$ & $\begin{array}{c}\text { Consultant } / \\
\text { Advisory } \\
\text { board }\end{array}$ & Other $^{3}$ \\
\hline Taylor M & - & - & - & - & - & - & $\begin{array}{l}\text { Bristol- } \\
\text { Myers } \\
\text { Squibb* }\end{array}$ \\
\hline Bressan RA & $\begin{array}{l}\text { UNIFES } \\
\text { P, CNPq } \\
\text { FAPESP } \\
\text { Instituto } \\
\text { Albert } \\
\text { Einstein } \\
\text { de } \\
\text { Ensino e } \\
\text { Pesquisa }\end{array}$ & - & $\begin{array}{c}\text { Novartis* } \\
\text { Eli-Lilly* } \\
\text { Janssen- } \\
\text { Cilag* } \\
\text { Astra- } \\
\text { Zeneca* }\end{array}$ & $\begin{array}{c}\text { Novartis*, } \\
\text { Eli-Lilly*, } \\
\text { Janssen- } \\
\text { Cilag*, Astra- } \\
\text { Zeneca *, }\end{array}$ & - & $\begin{array}{c}\text { Astra- } \\
\text { Zeneca*, } \\
\text { Janssen- } \\
\text { Cilag* }^{*}\end{array}$ & $\begin{array}{c}\text { Astra- } \\
\text { Zeneca*, } \\
\text { Janssen- } \\
\text { Cilag*, Uli- } \\
\text { Lily* }^{*}\end{array}$ \\
\hline Pan Neto P & $\begin{array}{c}\text { UNIFES } \\
\text { P }\end{array}$ & - & - & - & - & - & - \\
\hline Brietzke E & $\begin{array}{c}\text { UNIFES } \\
P\end{array}$ & $\mathrm{CNPq}$ & - & Jansen-Cilag & - & - & - \\
\hline
\end{tabular}




\section{References}

1. Merikangas KR, Akiskal HS, Angst J, Greenberg PE, Hirschfeld RM, Petukhova M, Kessler RC. Lifetime and 12-month prevalence of bipolar spectrum disorder in the National Comorbidity Survey replication. Arch Gen Psychiatry. 2007;64(5):543-552.

2. Merikangas KR, Jin R, He J-P, Kessler RC, Lee S, Sampson NA, Viana MC, Andrade LH, Hu C, Karam EG, Ladea M, Medina-Mora ME, Ono Y, Posada-Villa J, Sagar R, Wells JE, Zarkov Z. Prevalence and Correlates of Bipolar Spectrum Disorder in the World Mental Health Survey Initiative. Arch Gen Psychiatry. 2011;68(3):241-251.

3. Osby U, Brandt L, Correia N, Ekbom A, Sparén P. Excess mortality in bipolar and unipolar disorder in Sweden. Arch Gen Psychiatry. 2001;58(9):844-850.

4. Høyer EH, Mortensen PB, Olesen AV. Mortality and causes of death in a total national sample of patients with affective disorders admitted for the first time between 1973 and 1993. Br J Psychiatry. 2000;176:76-82.

5. Dutta R, Boydell J, Kennedy N, Van Os J, Fearon P, Murray RM. Suicide and other causes of mortality in bipolar disorder: a longitudinal study. Psychol Med. 2007;37(6):839-847.

6. Novick DM, Swartz HA, Frank E. Suicide attempts in bipolar I and bipolar II disorder: a review and meta-analysis of the evidence. Bipolar Disord. 2010;12(1):19 .

7. Baldessarini RJ, Bolzani L, Cruz N, Jones PB, Lai M, Lepri B, Perez J, Salvatore P, Tohen M, Tondo L, Vieta E. Onset-age of bipolar disorders at six international sites. J Affect Disord. 2010;121(1-2):143-146.

8. Hamshere ML, Gordon-Smith K, Forty L, Jones L, Caesar S, Fraser C, Hyde S, Tredget J, Kirov G, Jones I, Craddock N, Smith DJ. Age-at-onset in bipolar-I disorder: mixture analysis of 1369 cases identifies three distinct clinical sub-groups. J Affect Disord. 2009;116(1-2):23-29.

9. Tohen M, Zarate CA Jr, Hennen J, Khalsa HM, Strakowski SM, Gebre-Medhin P, Salvatore P, Baldessarini RJ. The McLean-Harvard First-Episode Mania Study: prediction of recovery and first recurrence. Am J Psychiatry. 2003;160(12):20992107.

10. Yatham LN, Kauer-Sant'Anna M, Bond DJ, Lam RW, Torres I. Course and outcome after the first manic episode in patients with bipolar disorder: prospective 12-month data from the Systematic Treatment Optimization Program For Early Mania project. Can J Psychiatry. 2009;54(2):105-112.

11. Baldessarini RJ, Salvatore P, Khalsa H-MK, Gebre-Medhin P, Imaz H, González-Pinto A, Perez J, Cruz N, Maggini C, Tohen M. Morbidity in 303 first-episode bipolar I disorder patients. Bipolar Disord. 2010;12(3):264-270.

12. Forty L, Jones L, Jones I, Smith DJ, Caesar S, Fraser C, Gordon-Smith K, Hyde S, Craddock N. Polarity at illness onset in bipolar I disorder and clinical course of illness. Bipolar Disord. 2009;11(1):82-88.

13. Suppes T, Leverich GS, Keck PE, Nolen WA, Denicoff KD, Altshuler LL, McElroy SL, Rush AJ, Kupka R, Frye MA, Bickel M, Post RM. The Stanley Foundation Bipolar Treatment Outcome Network. II. Demographics and illness characteristics of the first 261 patients. J Affect Disord. 2001;67(1-3):45-59.

14. Hirschfeld RMA, Lewis L, Vornik LA. Perceptions and impact of bipolar disorder: how far have we really come? Results of the national depressive and manic-depressive association 2000 survey of individuals with bipolar disorder. $J$ Clin Psychiatry. 2003;64(2):161-174.

15. Berk M, Dodd S, Callaly P, Berk L, Fitzgerald P, de Castella AR, Filia S, Filia K, Tahtalian S, Biffin F, Kelin K, Smith M, Montgomery W, Kulkarni J. History of illness prior to a diagnosis of bipolar disorder or schizoaffective disorder. J Affect Disord. 2007;103(1-3):181-186.

16. Gazalle FK, Andreazza AC, Ceresér KM, Hallal PC, Santin A, Kapczinski F. Clinical impact of late diagnose of bipolar disorder. J Affect Disord. 2005;86(23):313-316.

17. Post RM, Leverich GS, Kupka RW, Keck PE Jr, McElroy SL, Altshuler LL, Frye MA, Luckenbaugh DA, Rowe M, Grunze H, Suppes T, Nolen WA. Earlyonset bipolar disorder and treatment delay are risk factors for poor outcome in adulthood. J Clin Psychiatry. 2010;71(7):864-872.

18. Goldberg JF, Ernst CL. Features associated with the delayed initiation of mood stabilizers at illness onset in bipolar disorder. J Clin Psychiatry. 2002;63(11):985-991.

19. McCombs JS, Ahn J, Tencer T, Shi L. The impact of unrecognized bipolar disorders among patients treated for depression with antidepressants in the fee-forservices California Medicaid (Medi-Cal) program: a 6-year retrospective analysis. J Affect Disord. 2007;97(1-3):171-179.
20. Mitchell PB, Goodwin GM, Johnson GF, Hirschfeld RMA. Diagnostic guidelines for bipolar depression: a probabilistic approach. Bipolar Disord. 2008;10(1 Pt 2):144-152.

21. Mitchell PB, Frankland A, Hadzi-Pavlovic D, Roberts G, Corry J, Wright A, Loo CK, Breakspear M. Comparison of depressive episodes in bipolar disorder and in major depressive disorder within bipolar disorder pedigrees. Br J Psychiatry. In press 2011.

22. Forty L, Smith D, Jones L, Jones I, Caesar S, Cooper C, Fraser C, GordonSmith K, Hyde S, Farmer A, McGuffin P, Craddock N. Clinical differences between bipolar and unipolar depression. Br J Psychiatry. 2008;192(5):388-389.

23. Angst J, Adolfsson R, Benazzi F, Gamma A, Hantouche E, Meyer TD, Skeppar P, Vieta E, Scott J. The HCL-32: towards a self-assessment tool for hypomanic symptoms in outpatients. J Affect Disord. 2005;88(2):217-233.

24. Ghaemi SN, Miller CJ, Berv DA, Klugman J ,Rosenquist KJ, Pies RW. Sensitivity and specificity of a new bipolar spectrum diagnostic scale. $J$ Affect Disord. 2005;84(2-3):273-277.

25. Smith DJ, Griffiths E, Kelly M, Hood K, Craddock N, Simpson SA. Unrecognised bipolar disorder in primary care patients with depression. $\mathrm{Br} J$ Psychiatry. 2011;199:49-56.

26. Angst J, Gamma A, Benazzi F, Ajdacic V, Eich D, Rössler W. Toward a redefinition of subthreshold bipolarity: epidemiology and proposed criteria for bipolar-II, minor bipolar disorders and hypomania. J Affect Disord. 2003;73(12):133-146.

27. Kessler RC, Berglund P, Demler O, Jin R, Merikangas KR, Walters EE. Lifetime prevalence and age-of-onset distributions of DSM-IV disorders in the National Comorbidity Survey Replication. Arch Gen Psychiatry. 2005;62(6):593-602.

28. Angst J, Cui L, Swendsen J, Rothen S, Cravchik A, Kessler RC, Merikangas KR. Major depressive disorder with subthreshold bipolarity in the National Comorbidity Survey Replication. Am J Psychiatry. 2010;167(10):1194-1201.

29. Salvatore P, Baldessarini RJ, Tohen M, Khalsa HM, Sanchez-Toledo JP, Zarate CA Jr, Vieta E, Maggini C. McLean-Harvard International First-Episode Project: two-year stability of DSM-IV diagnoses in 500 first-episode psychotic disorder patients. J Clin Psychiatry. 2009;70(4):458-466.

30. Merikangas KR, Herrell R, Swendsen J, Rössler W, Ajdacic-Gross V, Angst J. Specificity of Bipolar Spectrum Conditions in the Comorbidity of Mood and Substance Use Disorders: Results From the Zurich Cohort Study. Arch Gen Psychiatry. 2008;65(1):47-52.

31. Correll CU, Smith CW, Auther AM, McLaughlin D, Shah M, Foley C, Olsen R, Lencz T, Kane JM, Cornblatt BA. Predictors of remission, schizophrenia, and bipolar disorder in adolescents with brief psychotic disorder or psychotic disorder not otherwise specified considered at very high risk for schizophrenia. J Child Adolesc Psychopharmacol. 2008;18(5):475-490.

32. Grant BF, Stinson FS, Hasin DS, Dawson DA, Chou SP, Ruan WJ, Huang B. Prevalence, correlates, and comorbidity of bipolar I disorder and axis I and II disorders: results from the National Epidemiologic Survey on Alcohol and Related Conditions. J Clin Psychiatry. 2005;66(10):1205-1215.

33. Gunderson JG, Weinberg I, Daversa MT, Kueppenbender KD, Zanarini MC, Shea MT, Skodol AE, Sanislow CA, Yen S, Morey LC, Grilo CM, McGlashan TH, Stout RL, Dyck I. Descriptive and longitudinal observations on the relationship of borderline personality disorder and bipolar disorder. Am J Psychiatry. 2006;163(7):1173-1178.

34. Kraepelin E. Lifetime Editions of Kraepelin in English. Bristol: Thoemmes Press; 2002.

35. Kessing LV, Andersen PK, Mortensen PB, Bolwig TG. Recurrence in affective disorder. I. Case register study. Br J Psychiatry. 1998;172:23-28.

36. Kessing LV, Hansen MG, Andersen PK. Course of illness in depressive and bipolar disorders. Naturalistic study, 1994-1999. Br J Psychiatry. 2004;185:372-377.

37. Kessing LV, Hansen MG, Andersen PK, Angst J. The predictive effect of episodes on the risk of recurrence in depressive and bipolar disorders - a life-long perspective. Acta Psychiatr Scand. 2004;109(5):339-344.

38. Robinson LJ, Ferrier IN. Evolution of cognitive impairment in bipolar disorder: a systematic review of cross-sectional evidence. Bipolar Disord. 2006;8(2):103-116.

39. Torres IJ, DeFreitas CM, DeFreitas VG, Bond DJ, Kunz M, Honer WG, Lam RW, Yatham LN. Relationship between cognitive functioning and 6-month clinical and functional outcome in patients with first manic episode bipolar I disorder. Psychol Med. 2011;41(5):971-982. 
40. Rosa AR, Reinares M, Franco C, Comes M, Torrent C, Sánchez-Moreno J, Martínez-Arán A, Salamero M, Kapczinski F, Vieta E. Clinical predictors of functional outcome of bipolar patients in remission. Bipolar Disord. 2009;11(4):401-409.

41. Berk M, Brnabic A, Dodd S, Kelin K, Tohen M, Malhi GS, Berk L, Conus P, McGorry PD. Does stage of illness impact treatment response in bipolar disorder? Empirical treatment data and their implication for the staging model and early intervention. Bipolar Disord. 2011;13(1):87-98.

42. Bratti IM, Baldessarini RJ, Baethge C, Tondo L. Pretreatment episode count and response to lithium treatment in manic-depressive illness. Harv Rev Psychiatry. 2003;11(5):245-256.

43. Scott J, Colom F, Vieta E. A meta-analysis of relapse rates with adjunctive psychological therapies compared to usual psychiatric treatment for bipolar disorders. Int J.Neuropsychopharmacol. 2007;10(1):123-129.

44. Kempton MJ, Geddes JR, Ettinger U, Williams SCR, Grasby PM. Metaanalysis, database, and meta-regression of 98 structural imaging studies in bipolar disorder. Arch Gen Psychiatry. 2008;65(9):1017-1032.

45. Hallahan B, Newell J, Soares JC, Brambilla P, Strakowski SM, Fleck DE, Kieseppä T, Altshuler LL, Fornito A, Malhi GS, McIntosh AM, Yurgelun-Todd DA, Labar KS, Sharma V, MacQueen GM, Murray RM, McDonald C. Structural magnetic resonance imaging in bipolar disorder: an international collaborative mega-analysis of individual adult patient data. Biol Psychiatry. 2011;69(4):326-335. 46. Post RM, Weiss SR. A speculative model of affective illness cyclicity based on patterns of drug tolerance observed in amygdala-kindled seizures. Mol Neurobiol. 1996;13(1):33-60.

47. Post RM. Kindling and sensitization as models for affective episode recurrence, cyclicity, and tolerance phenomena. Neurosci Biobehav Rev. 2007;31(6):858-873.

48. Kapczinski F, Vieta E, Andreazza AC, Frey BN, Gomes FA, Tramontina J, Kauer-Sant'anna M, Grassi-Oliveira R, Post RM. Allostatic load in bipolar disorder: Implications for pathophysiology and treatment. Neurosci Biobehav Rev. 2008;32(4):675-692.

49. Berk M, Kapczinski F, Andreazza AC, Dean OM, Giorlando F, Maes M, Yücel M, Gama CS, Dodd S, Dean B, Magalhäes PV, Amminger P, McGorry P, Malhi GS. Pathways underlying neuroprogression in bipolar disorder: focus on inflammation, oxidative stress and neurotrophic factors. Neurosci Biobehav Rev. 2011;35(3):804-817.

50. Kapczinski F, Frey BN, Kauer-Sant'Anna M, Grassi-Oliveira R. Brain-derived neurotrophic factor and neuroplasticity in bipolar disorder. Expert Rev Neurother. 2008;8(7):1101-1113.

51. Stork C, Renshaw PF. Mitochondrial dysfunction in bipolar disorder: evidence from magnetic resonance spectroscopy research. Mol Psychiatry. 2005;10(10):900-919.

52. Andreazza AC, Kauer-Sant'anna M, Frey BN, Bond DJ, Kapczinski F, Young LT, Yatham LN. Oxidative stress markers in bipolar disorder: a meta-analysis. $J$ Affect Disord. 2008;111(2-3):135-144.

53. Goodwin GM. Evidence-based guidelines for treating bipolar disorder: revised second edition--recommendations from the British Association for Psychopharmacology. J Psychopharmacol. (Oxford). 2009;23(4):346-388.

54. Beynon S, Soares-Weiser K, Woolacott N, Duffy S, Geddes JR. Psychosocial interventions for the prevention of relapse in bipolar disorder: systematic review of controlled trials. Br J Psychiatry. 2008;192(1):5-11.

55. Weiss RD, Ostacher MJ, Otto MW, et al. Does recovery from substance use disorder matter in patients with bipolar disorder? J Clin Psychiatry. 2005;66(6):730735; quiz 808-809.

56. Sachs GS, Thase ME, Otto MW, Bauer M, Miklowitz D, Wisniewski SR, Lavori P, Lebowitz B, Rudorfer M, Frank E, Nierenberg AA, Fava M, Bowden C, Ketter T, Marangell L, Calabrese J, Kupfer D, Rosenbaum JF. Rationale, design, and methods of the systematic treatment enhancement program for bipolar disorder (STEP-BD). Biol Psychiatry. 2003;53(11):1028-1042.

57. van der Loos MLM, Mulder P, Hartong EGTM, Blom MB, Vergouwen AC, van Noorden MS, Timmermans MA, Vieta E, Nolen WA; LamLit Study Group. Efficacy and safety of two treatment algorithms in bipolar depression consisting of a combination of lithium, lamotrigine or placebo and paroxetine. Acta Psychiatr Scand. 2010;122(3):246-254.

58. Geddes JR, Goodwin GM, Rendell J, Azorin JM, Cipriani A, Ostacher MJ, Morriss R, Alder N, Juszczak E. Lithium plus valproate combination therapy versus monotherapy for relapse prevention in bipolar I disorder (BALANCE): a randomised open-label trial. Lancet. 2010;375(9712):385-395.
59. Grunze H, Vieta E, Goodwin GM, Bowden C, Licht RW, Möller HJ, Kasper S. The World Federation of Societies of Biological Psychiatry (WFSBP) Guidelines for the Biological Treatment of Bipolar Disorders: Update 2010 on the treatment of acute bipolar depression. World J. Biol. Psychiatry. 2010;11(2):81-109.

60. Kauer-Sant'Anna M, Bond DJ, Lam RW, Yatham LN. Functional outcomes in first-episode patients with bipolar disorder: a prospective study from the Systematic Treatment Optimization Program for Early Mania project. Compr Psychiatry. 2009;50(1):1-8.

61. Grunze H, Kasper S, Goodwin G, Bowden C, Möller H-J. The World Federation of Societies of Biological Psychiatry (WFSBP) guidelines for the biological treatment of bipolar disorders, part III: maintenance treatment. World J Biol Psychiatry. 2004;5(3):120-135.

62. Cipriani A, Pretty H, Hawton K, Geddes JR. Lithium in the prevention of suicidal behavior and all-cause mortality in patients with mood disorders: a systematic review of randomized trials. Am J Psychiatry. 2005;162(10):1805-1819.

63. Colom F, Vieta E, Sánchez-Moreno J, Palomino-Otiniano R, Reinares M, Goikolea JM, Benabarre A, Martínez-Arán A. Group psychoeducation for stabilised bipolar disorders: 5-year outcome of a randomised clinical trial. Br J Psychiatry. 2009;194(3):260-265.

64. Petersen L, Jeppesen P, Thorup A, Abel MB, Øhlenschlaeger J, Christensen TØ, Krarup G, Jørgensen P, Nordentoft M. A randomised multicentre trial of integrated versus standard treatment for patients with a first episode of psychotic illness. BMJ. 2005;331(7517):602.

65. Gafoor R, Landau S, Craig TKJ, Elanjithara T, Power P, McGuire P. Esquire trial: efficacy and adverse effects of quetiapine versus risperidone in first-episode schizophrenia. J Clin Psychopharmacol. 2010;30(5):600-606.

66. Kessing LV, Hansen HV, Christensen EM, Dam H, Gluud C, Wetterslev J. The effects of centralised and specialised combined pharmacological and psychological intervention compared with decentralised and non-specialised treatment in the early course of severe unipolar and bipolar affective disorders--design of two randomised clinical trials. Trials. 2011;12(1):32.

67. Berk M, Conus P, Lucas N, Hallam K, Malhi GS, Dodd S, Yatham LN, Yung A, McGorry P. Setting the stage: from prodrome to treatment resistance in bipolar disorder. Bipolar Disord. 2007;9(7):671-678.

68. Howes OD, Lim S, Theologos G, Yung AR, Goodwin GM, McGuire P. A comprehensive review and model of putative prodromal features of bipolar affective disorder. Psychol Med. 2011;41(8):1567-1577.

69. Skjelstad DV, Malt UF, Holte A. Symptoms and signs of the initial prodrome of bipolar disorder: a systematic review. J Affect Disord. 2010;126(1-2):1-13.

70. Olvet DM, Stearns WH, McLaughlin D, Auther AM, Correll CU, Cornblatt BA. Comparing clinical and neurocognitive features of the schizophrenia prodrome to the bipolar prodrome. Schizophr Res. 2010;123(1):59-63.

71. Craddock N, Sklar P. Genetics of bipolar disorder: successful start to a long journey. Trends Genet. 2009;25(2):99-105.

72. McGuffin P, Rijsdijk F, Andrew M, Sham P, Katz R, Cardno A. The heritability of bipolar affective disorder and the genetic relationship to unipolar depression. Arch Gen Psychiatry. 2003;60(5):497-502.

73. Kieseppa T, Partonen T, Haukka J, Kaprio J, Lonnqvist J. High Concordance of Bipolar I Disorder in a Nationwide Sample of Twins. Am J Psychiatry. 2004;161(10):1814-1821.

74. Craddock N, Jones I. Genetics of bipolar disorder. J Med Genet. 1999;36(8):585-594.

75. DelBello MP, Geller B. Review of studies of child and adolescent offspring of bipolar parents. Bipolar Disord. 2001;3(6):325-334.

76. Birmaher B, Axelson D, Monk K, Kalas C, Goldstein B, Hickey MB, Obreja M, Ehmann M, Iyengar S, Shamseddeen W, Kupfer D, Brent D. Lifetime psychiatric disorders in school-aged offspring of parents with bipolar disorder: the Pittsburgh Bipolar Offspring study. Arch Gen Psychiatry. 2009;66(3):287296.

77. Zappitelli MC, Bordin IA, Hatch JP, Caetano SC, Zunta-Soares G, Olvera RL, Soares JC. Lifetime psychopathology among the offspring of Bipolar I parents. Clinics (Sao Paulo). 2011;66(5):725-730.

78. Bechdolf A, Nelson B, Cotton SM, Chanen A, Thompson A, Kettle J, Conus P, Amminger GP, Yung AR, Berk M, McGorry PD. A preliminary evaluation of the validity of at-risk criteria for bipolar disorders in help-seeking adolescents and young adults. J Affect Disord. 2010;127(1-3):316-320. 
79. Chang KD, Dienes K, Blasey C, Adleman N, Ketter T, Steiner H. Divalproex monotherapy in the treatment of bipolar offspring with mood and behavioral disorders and at least mild affective symptoms. J Clin Psychiatry. 2003;64(8):936942.

80. DelBello MP, Adler CM, Whitsel RM, Stanford KE, Strakowski SM. A 12-week single-blind trial of quetiapine for the treatment of mood symptoms in adolescents at high risk for developing bipolar I disorder. J Clin Psychiatry. 2007;68(5):789-795.

81. Miklowitz DJ, Chang KD, Taylor DO, George EL, Singh MK, Schneck CD, Dickinson LM, Howe ME, Garber J. Early psychosocial intervention for youth at risk for bipolar I or II disorder: a one-year treatment development trial. Bipolar Disord. 2011;13(1):67-75. 